\title{
Enxofre elementar no manejo do pH de substrato orgânico alcalino
}

\author{
Elemental sulfur for $\mathrm{pH}$ management of alkaline organic substrates
}

\author{
Vinicius Boaro $^{\mathrm{I}^{*}}$ Sergio Francisco Schwarz ${ }^{\mathrm{I}}$ Paulo Vitor Dutra de Souza ${ }^{\mathrm{I}}$ \\ Wagner Soares ${ }^{I}$ Gil Vicente Lourosa ${ }^{I}$
}

\section{RESUMO}

\begin{abstract}
Embora existam recomendações agronômicas consolidadas para a elevação do pH de substratos orgânicos, poucas são as informações disponíveis para a redução. Porém, a crescente utilização de matérias-primas alternativas às tradicionais torna necessário o emprego de métodos para diminuição do $\mathrm{pH}$, já que alguns materiais com boas características físicas e biológicas são alcalinos e incompatíveis com o cultivo da maioria das espécies. Os objetivos do presente trabalho foram verificar a eficiencia do enxofre elementar $\left(S^{\circ}\right)$ na diminuição do $\mathrm{pH}$ de um substrato orgânico alcalino e avaliar um critério para determinação da dose a ser adicionada. Para tanto, testou-se a mistura de cinco doses de $S^{0}$ a um substrato comercial composto por casca de eucalipto compostada (0, 4, 8, 12 e $16 \mathrm{~g} \mathrm{~S}^{0} \mathrm{dm}^{-3}$ de substrato), com base no valor do seu poder de neutralização (PN). Avaliou-se o pH e a condutividade elétrica (CE) dos substratos. Observou-se que o $S^{0} e ́$ eficiente na redução do $\mathrm{pH}$ de substratos orgânicos, mas acarreta aumento da CE. O PN do substrato é um critério confiável para balizar a determinação da dose de $S^{0}$ a ser utilizada.
\end{abstract}

Palavras-chave: propagação de plantas, substratos hortícolas, nutrição, poder de neutralização.

\section{ABSTRACT}

Although agronomic recommendations for raising the $\mathrm{pH}$ of organic substrates are consolidated, little information is available for its reduction. The increasing use of alternative raw materials, however, makes it necessary to develop methods for decreasing $\mathrm{pH}$, since some materials with good physical and biological properties are alkaline and are not recommended for the majority of species. The objective of this research was to determine the efficiency of elemental sulfur $\left(S^{0}\right)$ in decreasing the $\mathrm{pH}$ of an alkaline substrate, and evaluate a method to calculate the dose to be added. It was evaluated the mixture of five doses of $S^{0}$ to a commercial substrate compound of composted eucalyptus bark $(0$, 4, 8, 12 and $16 \mathrm{~g} \mathrm{~S}^{0} \mathrm{dm}^{-3}$ substrate), based on its neutralizing value $(N V)$. The $\mathrm{pH}$ and electrical conductivity $(E C)$ of the substrates were assessed. The $S^{0}$ is effective in reducing the $\mathrm{pH}$ of organic substrates, but it causes increases in EC. The NV of the substrate is a reliable criterion for guiding the determination of the $S^{0}$ dose to be added.

Key words: plants propagation, horticultural substrates, nutrition, neutralizing value.

\section{INTRODUÇÃO}

Embora existam recomendações agronômicas consolidadas para a elevação do pH de substratos orgânicos, poucas são as informações disponíveis para sua redução (MAGALHÃES et al., 2005). Porém, a crescente utilização de substratos com diferentes matérias-primas torna necessário o emprego de corretivos que atuem na diminuição do $\mathrm{pH}$, já que alguns materiais, ao mesmo tempo que apresentam boas características físicas e biológicas, são alcalinos e incompatíveis com o cultivo da maioria das espécies. De modo geral, para substratos de base orgânica, recomenda-se que o $\mathrm{pH}$ esteja entre 5,2 e 5,5 (SCHMITZ et al., 2002). Meios de cultivo com $\mathrm{pH}$ menor do que 5,0 estão associados à deficiência de nutrientes como nitrogênio $(\mathrm{N})$, potássio $(\mathrm{K})$, cálcio $(\mathrm{Ca})$ e magnésio $(\mathrm{Mg})$ nas plantas, enquanto que, quando o $\mathrm{pH}$ encontra-se acima de 6,5, tendem a ocorrer problemas de disponibilidade de fósforo $(\mathrm{P})$ e micronutrientes, como ferro (Fe), manganês $(\mathrm{Mn})$, zinco $(\mathrm{Zn})$ e cobre (Cu) (KÄMPF, 2005).

Apesar do conhecimento a cerca do comportamento dos substratos em termos de disponibilidade de nutrientes em função do seu pH, a

IDepartamento de Horticultura e Silvicultura, Faculdade de Agronomia, Universidade Federal do Rio Grande do Sul (UFRGS), Av. Bento Gonçalves, 7712, 91501-970, Porto Alegre, RS, Brasil. E-mail: vinicius@agriflora.agr.br. *Autor para correspondência. 
escassez de informações que auxiliem na manutenção do seu valor, de modo a se adequar às necessidades das plantas, pode ser considerada um fator limitante e que acarreta a necessidade de novos estudos. Um corretivo muito utilizado para diminuição do $\mathrm{pH}$ de solos minerais em regiões com problemas de alcalinidade é o enxofre elementar $\left(\mathrm{S}^{0}\right)$. $\mathrm{O}$ seu efeito acidificante está associado à oxidação deste por microrganismos, com consequente formação de ácido sulfúrico e posterior liberação de íons de hidrogênio na solução (HEYDARNEZHAD et al., 2012).

Os microrganismos envolvidos no processo de oxidação são, principalmente, bactérias do gênero Thiobacillus (HEYDARNEZHAD et al., 2012). Além dos microrganismos, fatores físicos do substrato influenciam na taxa de oxidação do S, como a umidade, aeração, temperatura e teor de matéria orgânica (ORMAN \& KAPLAN, 2011).

A oxidação do $\mathrm{S}$ elementar ocorre em temperaturas entre 4 e $45^{\circ} \mathrm{C}$, com uma faixa ótima entre 25 e $40^{\circ} \mathrm{C}$ (SIERRA et al., 2007). Quanto à umidade, baixos teores de água limitam a atividade microbiana e reduzem a acessibilidade às partículas de $\mathrm{S}$, que são altamente hidrofóbicas. Porém, teores elevados de umidade reduzem significativamente a oxidação, como consequência da baixa aeração do substrato. Já com relação à matéria orgânica, maiores teores favorecem a oxidação, o que está associado à utilização desta como fonte de energia e carbono pelos microrganismos (SIERRA et al., 2007).

Apesar do conhecimento a respeito dos inúmeros fatores envolvidos no processo de oxidação do $S^{0}$, existe uma carência de informações que balizam a utilização deste como corretor do $\mathrm{pH}$ de substratos orgânicos, sendo importante o desenvolvimento de estudos que estabeleçam parâmetros para a adoção correta desta prática. Nesse sentido, o poder de neutralização (PN) do substrato constitui-se num indicativo do poder tamponante de acidez do material, expresso em equivalente de $\mathrm{CaCO}_{3}$, a partir do qual se pode calcular a quantidade de íons $\mathrm{H}^{+}$necessária para neutralizar toda a quantidade de íons $\mathrm{OH}^{-}$passível de ser formada no substrato, podendo ser um critério confiável para determinação da dose demandada para correção do $\mathrm{pH}$. O presente trabalho objetivou verificar a eficiência do $\mathrm{S}^{0}$ na diminuição do $\mathrm{pH}$ de um substrato orgânico alcalino, bem como avaliar um critério para determinação da dose de $\mathrm{S}^{0}$ a ser adicionada.

\section{MATERIAL E MÉTODOS}

O trabalho foi conduzido entre setembro e dezembro de 2012 (80 dias), em casa de vegetação situada na Faculdade de Agronomia da Universidade Federal do Rio Grande do Sul, em Porto Alegre/RS. Foram testadas cinco doses de S elementar (DSE), misturadas manualmente e de forma homogênea a um substrato comercial alcalino, composto basicamente por casca de eucalipto compostada e cujas características químicas são apresentadas na tabela 1 , com três repetições por tratamento. As diferentes $\operatorname{DSE}\left(0,0 ; 4,0 ; 8,0 ; 12,0\right.$ e $16,0 \mathrm{~g} \mathrm{~S}^{0} \mathrm{dm}^{-3}$ de substrato), obtidas através de um produto comercial com $99 \%$ de pureza, foram determinadas com base na densidade seca do substrato, o que ocorreu da seguinte forma: a) determinou-se o PN, em porcentagem de equivalente a $\mathrm{CaCO}_{3}$, do substrato, no Laboratório de Análises de Solos e Tecidos da Faculdade de Agronomia da UFRGS; b) a partir do valor do PN, calculou-se a quantidade de íons $\mathrm{H}^{+}$, em gramas, necessária para neutralizar todos os íons $\mathrm{OH}^{-}$que o substrato era capaz de liberar para a solução; c) conhecendo-se a quantidade, em gramas, de íons $\mathrm{H}^{+}$que cada grama de $\mathrm{S}^{0}$ formava após o processo de oxidação, calculou-se a dose exata de $\mathrm{S}^{0}$ para total neutralização dos $\mathrm{OH}^{-}$ do substrato; d) a partir das informações obtidas, estabeleceu-se a curva das doses de $\mathrm{S}^{0}$ a serem adicionadas ao substrato.

Tabela 1 - Características químicas do substrato comercial composto por casca de eucalipto compostada.

\begin{tabular}{ll}
\hline Determinação & Casca de eucalipto compostada \\
\hline $\mathrm{pH}$ & 7,80 \\
$\mathrm{CE}\left(\mathrm{mS} \mathrm{cm}^{-1}\right)$ & 0,98 \\
$\mathrm{P}$ extraível $\left(\mathrm{mg} \mathrm{kg}^{-1}\right)$ & 14,3 \\
$\mathrm{~K}$ extraível $\left(\mathrm{mg} \mathrm{kg}^{-1}\right)$ & 2105 \\
$\mathrm{Al}$ trocável $\left(\mathrm{cmol}_{\mathrm{c}} \mathrm{kg}^{-1}\right)$ & 0,0 \\
$\mathrm{Ca}$ trocável $\left(\mathrm{cmol}_{\mathrm{c}} \mathrm{kg}^{-1}\right)$ & 61,9 \\
$\mathrm{Mg}$ trocável $\left(\mathrm{cmol}_{\mathrm{c}} \mathrm{kg}^{-1}\right)$ & 10,7 \\
$\mathrm{~S}-\mathrm{SO}{ }_{4}^{2-}$ extraível $\left(\mathrm{mg} \mathrm{kg}^{-1}\right)$ & 601 \\
$\mathrm{Zn}$ extraível $\left(\mathrm{mg} \mathrm{kg}^{-1}\right)$ & 1,1 \\
$\mathrm{Cu}$ extraível $\left(\mathrm{mg} \mathrm{kg}^{-1}\right)$ & 0,2 \\
$\mathrm{~B}$ extraível $\left(\mathrm{mg} \mathrm{kg}^{-1}\right)$ & 5,4 \\
$\mathrm{Mn}$ trocável $\left(\mathrm{mg} \mathrm{kg}^{-1}\right)$ & 36,0 \\
Carbono orgânico total $(\%)$ & 8,2 \\
Saturação da CTC por bases $(\%)$ & 98 \\
PN (\%) & 7 \\
Al + H (cmol $\left.\mathrm{kg}^{-1}\right)$ & 1,2 \\
\hline
\end{tabular}

pH e CE (condutividade elétrica) determinados pelo método 1:5 (relação substrato:água; v:v) (densidade do substrato $=998 \mathrm{gdm}^{-3}$ ); $\mathrm{P}$ e K pelo método Mehlich1; carbono orgânico total por combustão úmida; $\mathrm{Ca}, \mathrm{Mg}, \mathrm{Al}, \mathrm{Mn}$ trocáveis extraídos com $\mathrm{KCl}$ $1 \mathrm{~mol} \mathrm{~L}^{-1} ; \mathrm{S}_{-} \mathrm{SO}_{4}{ }^{2-}$ extraído com $\mathrm{Ca}\left(\mathrm{H}_{2} \mathrm{PO}_{4}\right)_{2} 500 \mathrm{mgL}^{-1}$ de $\mathrm{P} ; \mathrm{Zn}$ e $\mathrm{Cu}$ extraídos com $\mathrm{HCl} 0,1 \mathrm{~mol} \mathrm{~L}^{-1}$; $\mathrm{B}$ extraído com água quente; $\mathrm{PN}=$ poder de neutralização, em equivalente $\mathrm{a} \mathrm{CaCO}_{3} ; \mathrm{Al}+\mathrm{H}=$ acidez potencial. 
Foram empregados $20 \mathrm{dm}^{3}$ de substrato, dispostos em bandejas com capacidade para 22,5 $\mathrm{dm}^{3}(15 \times 30 \times 50 \mathrm{~cm})$, contendo dez pequenos orifícios na superfície inferior, onde foi colocada uma tela para evitar a perda de substrato. Então, realizou-se a correção da umidade inicial do substrato $(37 \%)$ para $50 \%$, através da adição de $4,794 \mathrm{dm}^{3}$ de água destilada a cada tratamento (bandeja).

O substrato presente em cada recipiente foi revolvido a cada sete dias, de modo a aumentar a aeração na porção inferior do substrato no recipiente e, logo em seguida, era realizada a correção da umidade para $50 \%$, por meio da adição de água destilada, devido à redução do seu teor ao longo dos sete dias. A conferência do teor de umidade do substrato foi realizada com base na medição da massa dele.

Foram realizadas dez avaliações no período decorrente entre a mistura do substrato com o $\mathrm{S}^{0}$ e 80 dias após a mistura (DAM). As variáveis analisadas foram o valor do $\mathrm{pH}$ e a condutividade elétrica (CE) do substrato. Para tanto, foram retiradas amostras de cada tratamento aos 0, 4, $11,18,29,39,45,55,66$ e 80 DAM e enviadas para o Laboratório de Análises de Substratos para Plantas do Departamento de Horticultura e Silvicultura (Faculdade de Agronomia, UFRGS), onde foi realizada análise através do método 1:5 (relação substrato:água; v:v). Durante o período do experimento, a temperatura e a umidade relativa do ar no interior da casa de vegetação foram monitorados através de um termohigrômetro digital (marca TFA; modelo 303180), sendo que as variações podem ser observadas na figura 1 .

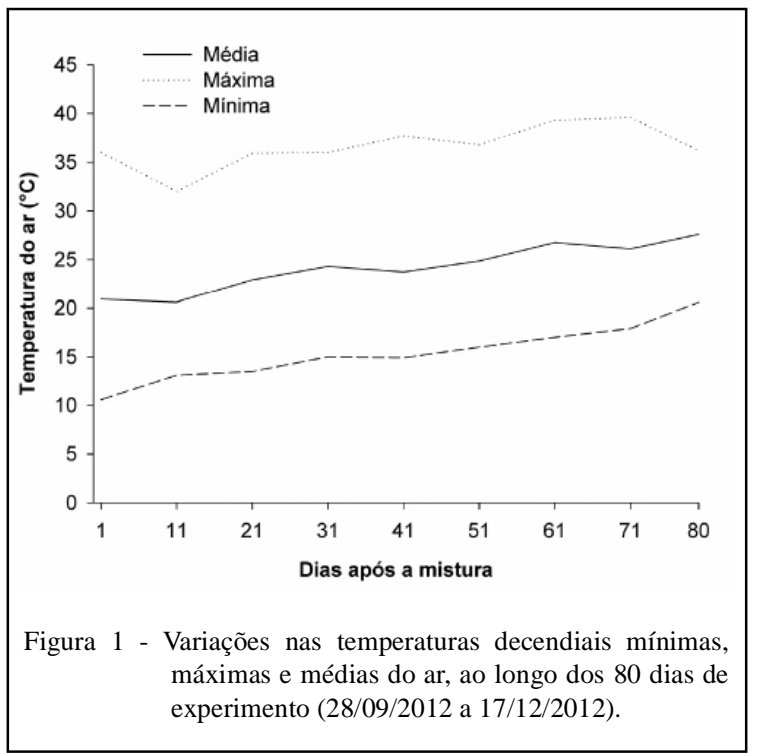

Os resultados foram submetidos à análise de variância, sendo as médias diferenciadas estatisticamente pelo teste de Tukey $(\mathrm{P}>0,05)$, e à análise de regressão polinomial.

\section{RESULTADOS E DISCUSSÃO}

A adição de $\mathrm{S}^{0}$ ao substrato reduziu o $\mathrm{pH}$ da sua solução (Figura $2 \mathrm{a}$ ), com consequente aumento da CE (Figura 2b), sendo a intensidade e magnitude desse efeito dependente da DSE utilizada. A análise de correlação entre o $\mathrm{pH}$ e a CE confirma essa relação, sendo significativa e inversa $(\mathrm{r}=-0,85$ e $\mathrm{P}<0,001$ ) (Figura 3), o que também foi observado por outros autores (SIERRA et al., 2007; BARBARO et al., 2010).

Para a variável $\mathrm{pH}$, percebe-se que a regressão foi significativa para todos os tratamentos e que, quanto maior a DSE adicionada, maior a velocidade e magnitude de redução do $\mathrm{pH}$ do substrato, corroborando os resultados de KÄMPF et al. (2009) e BARBARO et al. (2010). HEYDARNEZHAD et al. (2012) afirmam que, após a sua oxidação, cada mol de $\mathrm{S}^{0}$ gera dois moles de íons $\mathrm{H}^{+}$no substrato, reduzindo o $\mathrm{pH}$ do meio. As diferenças na variação do $\mathrm{pH}$, tanto em intensidade como no tempo, em função dos diferentes tratamentos, estão associadas à disponibilidade de $\mathrm{S}^{0}$ no substrato para a ocorrência da oxidação por parte dos microrganismos, e consequente formação de $\mathrm{H}_{2} \mathrm{SO}_{4}$, o que ocorre de forma lenta e gradual (CARRIÓN et al., 2008).

As variações observadas no tratamento testemunha são atribuídas à possível instabilidade do material testado. $\mathrm{O}$ alto teor de matéria orgânica, associado às temperaturas elevadas no decorrer do experimento (Figura 1), bem como a presença de umidade adequada e manuseio do material, podem ter promovido o aumento da atividade microbiana no substrato, resultando na alteração de características químicas deste (CAMPBELL et al., 1981).

Ao final do experimento (80 DAM), a análise de regressão foi significativa para a variável $\mathrm{pH}$, em função da DSE misturada ao substrato $(\mathrm{P}<0,001)$ (Figura 4a). No tratamento com $16 \mathrm{~g} \mathrm{~S}^{0}$ $\mathrm{dm}^{-3}$ de substrato, o $\mathrm{pH}$ atingiu um valor médio igual a 5,42, considerado adequado para a maioria das espécies (entre 5,2 e 5,5) (SCHMITZ et al., 2002). Com $12 \mathrm{~g} \mathrm{~S}^{0} \mathrm{dm}^{-3}$ de substrato, os valores ficam próximos da faixa ideal. Já para os demais tratamentos, o pH não reduziu suficientemente, distanciando-se significativamente da referida faixa. 


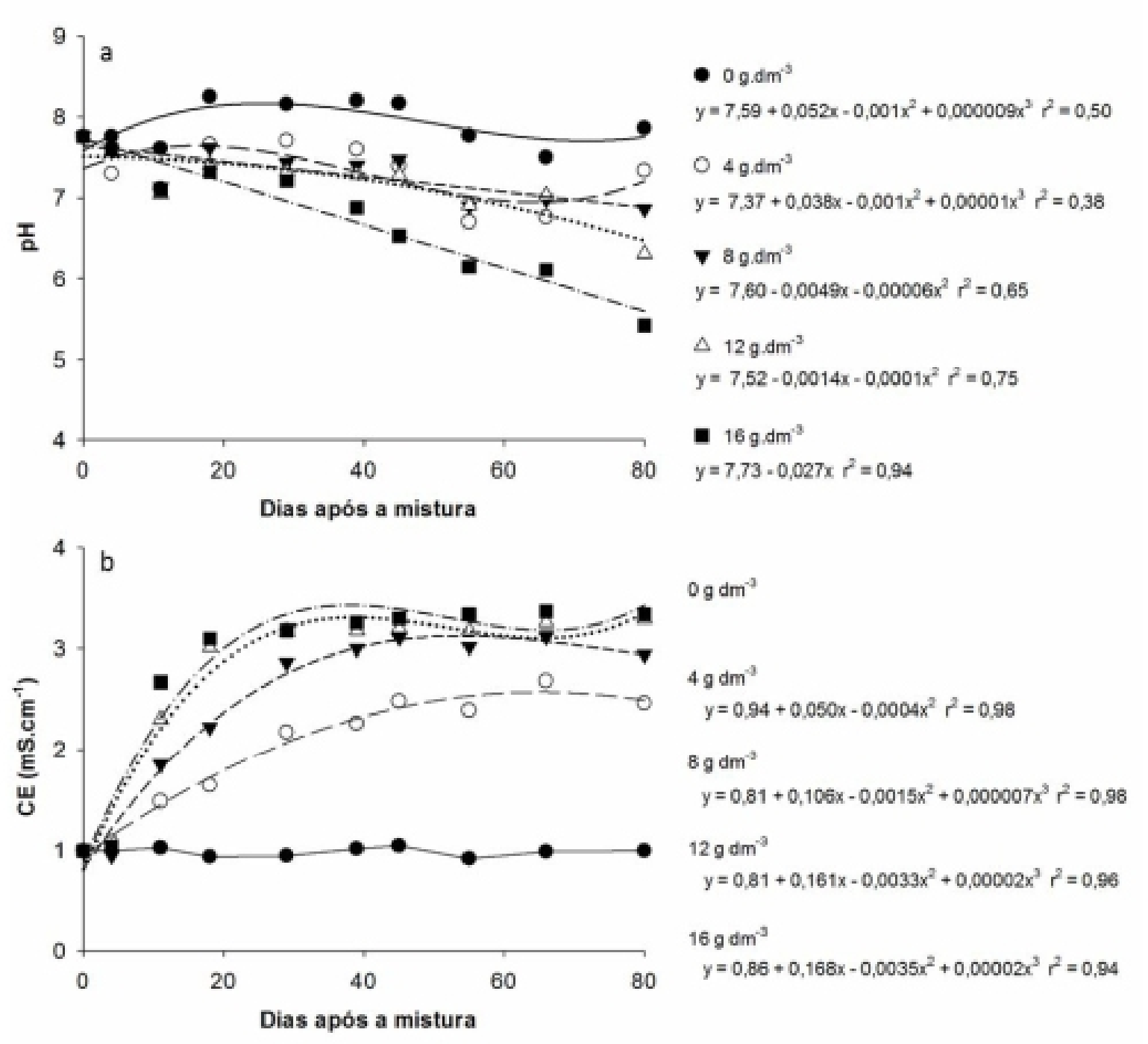

Figura 2 - Evolução do pH (a) e da condutividade elétrica (CE) (b) do substrato ao longo de 80 dias após a mistura, com as diferentes doses de enxofre elementar (média de 3 repetições; pH e CE determinados pelo método 1:5-v:v).

Com relação à $\mathrm{CE}$, a regressão não foi significativa $(\mathrm{P}>0,05)$ para $\mathrm{o}$ tratamento testemunha, indicando que não houve variações ao longo dos 80 dias de avaliação. Já para os tratamentos com adição de $\mathrm{S}^{0}$, a regressão foi significativa $(\mathrm{P}<0,05)$, sendo que maiores doses resultaram em incrementos mais expressivos da $\mathrm{CE}$ (Figura 2b). Ao final do experimento (80 DAM), a análise de regressão foi significativa $(P<0,001)$ para a variável $\mathrm{CE}$, apontando diferença entre as médias de CE dos substratos, em função da DSE adicionada (Figura 4b). Essas médias variaram entre 0,989 $\left(\right.$ sem S $\left.^{0}\right)$ e 3,343 $\left(16 \mathrm{~g} \mathrm{~S}^{0} \mathrm{dm}^{-3}\right.$ de substrato). Para o método de análise utilizado (relação substrato:água; v:v), valores normais de CE encontram-se na faixa entre 0,36 e $0,65 \mathrm{mS} \mathrm{cm}^{-}$ ${ }^{1}$. Valores acima de $1,10 \mathrm{mS} \mathrm{cm}^{-1}$ são considerados extremos, devendo causar injúrias à maioria das plantas cultivadas em recipientes (CAVINS, 2000). Frente a isso, percebe-se que o substrato utilizado já apresentava uma salinidade elevada, mesmo sem a adição de $\mathrm{S}$, no dia da instalação do experimento. Esse problema foi agravado após a mistura com $\mathrm{S}^{0}$, de tal forma que todos os tratamentos resultaram em níveis de salinidade acima do considerado extremo para substratos destinados ao cultivo de plantas. Entretanto, a umidade dele foi mantida entre 40 e $50 \%$ durante todo o experimento, não

Ciência Rural, v.44, n.12, dez, 2014. 


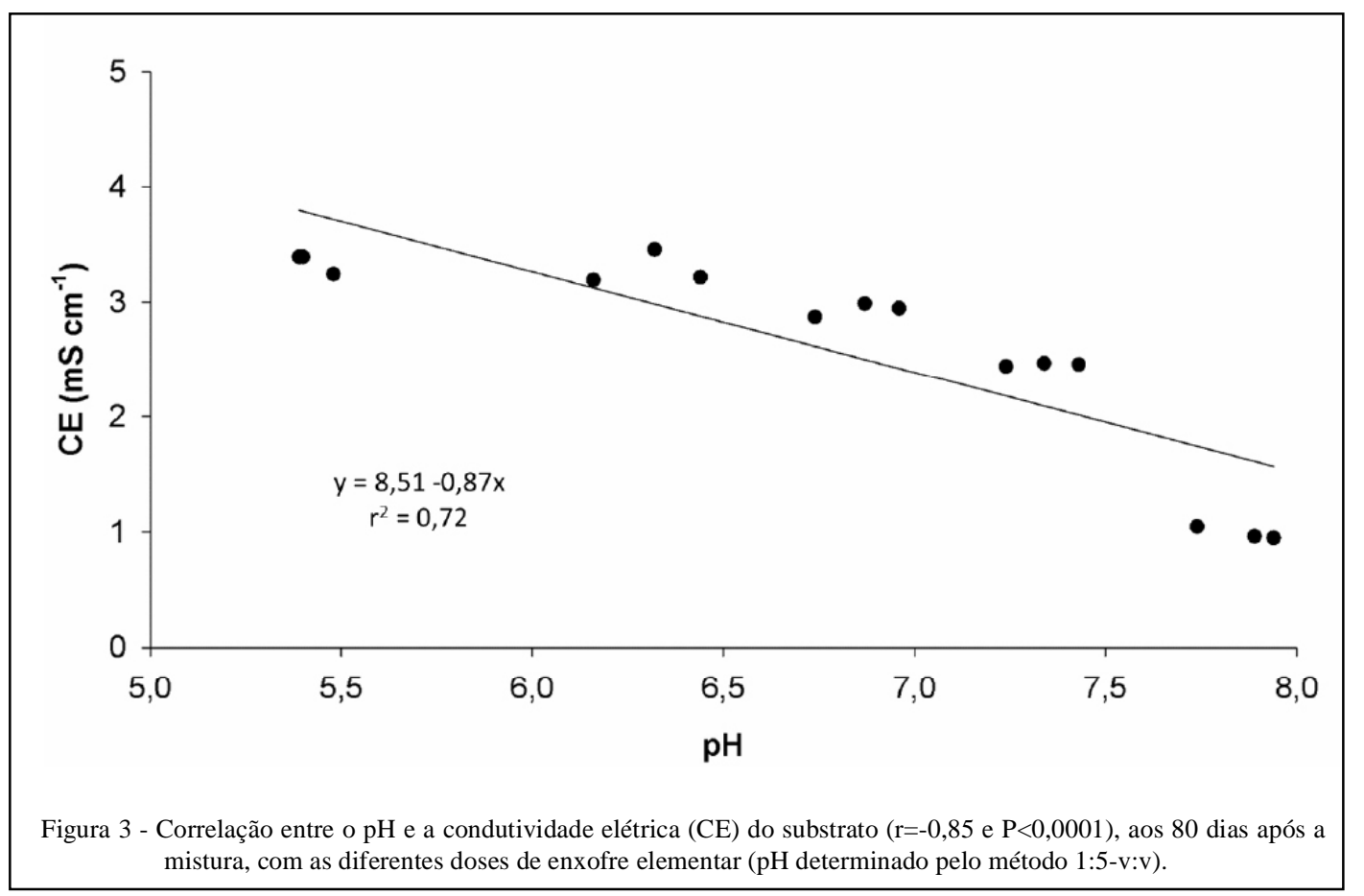

atingindo a saturação e, portanto, não ocorrendo a lixiviação dos sais formados após a oxidação do $\mathrm{S}^{0}$. Dessa forma, o manejo da irrigação pode ser uma alternativa eficiente para a adequação da $\mathrm{CE}$ em substratos com valores acima do recomendado, pois muitos autores atribuem a diminuição da CE de substratos à lixiviação dos sais durante a irrigação (FOCHESATO et al., 2008), sendo que a aceleração dessa redução pode ser obtida aumentando-se a frequência dos turnos de irrigação e/ou o tempo por turno.

Alguns autores condicionam a eficiência do $\mathrm{S}^{0}$ na redução do $\mathrm{pH}$ a algumas características do meio, as quais devem ser consideradas para a determinação da dose a ser adicionada. ORMAN \& KAPLAN (2011), para um solo calcário, relatam que a resposta à aplicação de $\mathrm{S}^{0}$ depende do teor de $\mathrm{CaCO}_{3}$ presente no meio, que confere ao solo ou substrato um maior ou menor poder tampão da acidez. LINDEMANN et al. (1991), ao adicionarem $\mathrm{S}^{0}$ a um solo da região do Novo México, Estados Unidos, verificaram que o $\mathrm{H}_{2} \mathrm{SO}_{4}$ produzido após a oxidação foi rapidamente neutralizado pelo $\mathrm{CaCO}_{3}$, não ocorrendo alteração no $\mathrm{pH}$. Nesse sentido, o PN do substrato mostrou-se um critério confiável para determinação da DSE demandada para correção do $\mathrm{pH}$. Para o substrato testado, cujo PN é 7\%, são necessárias 14,87 gramas de $\mathrm{S}^{0}$ por decímetro cúbico de substrato, visando à total neutralização das hidroxilas passíveis de serem liberadas pela fração sólida do substrato em sua solução. A presença de ânions ligados à cátions básicos, como o $\mathrm{Ca}, \mathrm{Mg}$ e o K, pode ser considerado o principal fator que confere ao substrato testado a característica alcalina e um alto PN.

Os resultados encontrados por SIERRA et al. (2007), ao avaliarem o efeito da aplicação de $\mathrm{S}^{0}$ como corretor de $\mathrm{pH}$ e na disponibilidade de nutrientes em seis solos chilenos, corroboram os do presente estudo. Os autores observaram que os diferentes solos apresentaram comportamentos distintos em função do $\mathrm{S}^{0}$ aplicado. Segundo eles, as características dos solos que mais influenciaram sobre a magnitude do efeito acidificante do $\mathrm{S}^{0}$ foram os teores de $\mathrm{CaCO}_{3}$, matéria orgânica e areia. Desse modo, as maiores reduções de $\mathrm{pH}$ ocorreram nos solos com menor capacidade tamponante, como consequência do menor teor de $\mathrm{CaCO}_{3}$ e matéria orgânica, sendo o efeito mais intenso com o passar do tempo. Os autores ainda concluem que a definição da DSE deve ser realizada mediante a análise de algumas características do solo, como o pH e teor de carbonatos e de matéria orgânica.

Portanto, a quantidade de equivalente a $\mathrm{CaCO}_{3}$ no substrato, expressa através do $\mathrm{PN}$, é, de fato, uma característica que pode ser utilizada como parâmetro para determinação da necessidade de produto acidificante a ser adicionada a ele.

Ciência Rural, v.44, n.12, dez, 2014. 

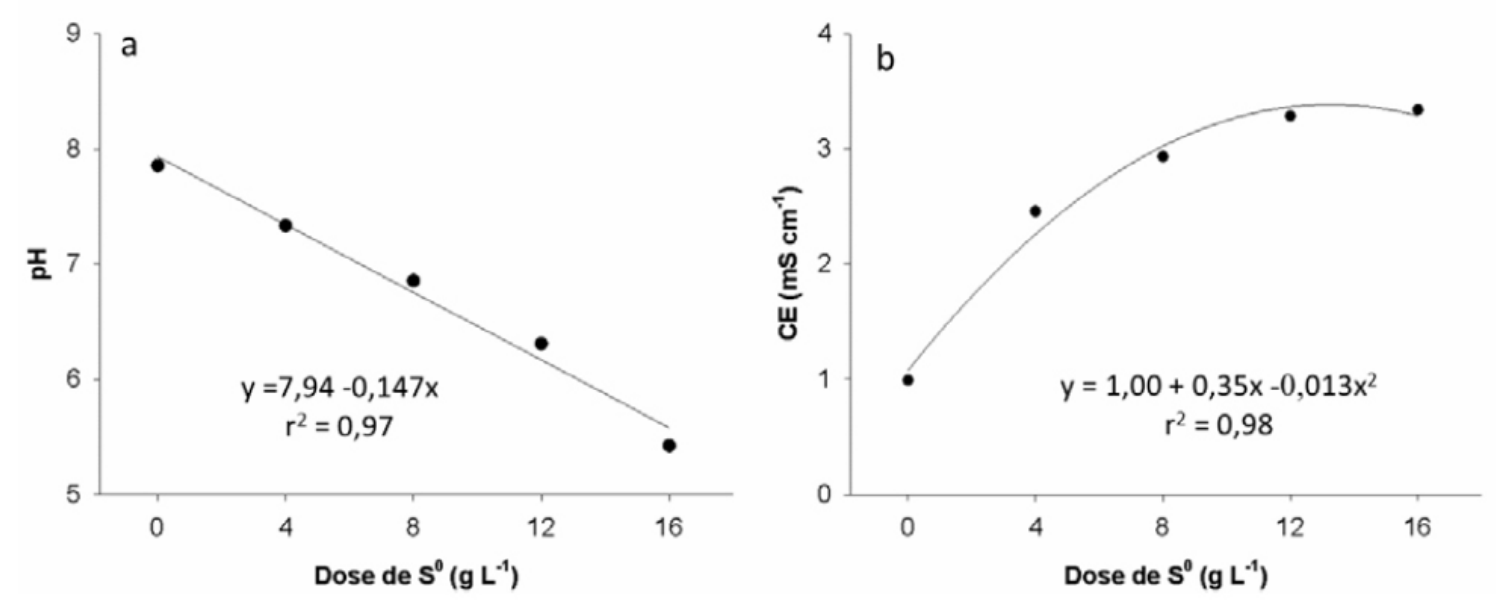

Figura 4 - Valor de pH (a) e condutividade elétrica (CE) (b) do substrato em função da dose de enxofre elementar adicionada, aos 80 dias após a mistura (média de 3 repetições; $\mathrm{pH}$ e CE determinados pelo método 1:5-v:v).

Todavia, deve-se atentar para o fato de que nem todos os íons $\mathrm{OH}^{-}$potencialmente formados serão realmente liberados na solução do substrato, e que o S adicionado não será oxidado em sua totalidade, já que dependem de inúmeros fatores que estão envolvidos nestes processos. Frente ao exposto, considera-se que a DSE a ser adicionada, calculada a partir do PN do substrato, consiste em um parâmetro para balizar o emprego dessa técnica, devendose testar uma curva, com doses acima e abaixo da calculada, para cada material a ser corrigido.

\section{CONCLUSÃO}

O S elementar é eficiente na redução do pH de substratos orgânicos, mas acarreta aumento da condutividade elétrica destes. $\mathrm{O}$ poder de neutralização do substrato é um critério confiável para balizar a determinação da dose de S elementar a ser adicionada.

\section{AGRADECIMENTOS}

Agradecemos ao Conselho Nacional de Desenvolvimento Científico e Tecnológico (CNPq) e à Fundação de Amparo à Pesquisa do Estado do Rio Grande do Sul (FAPERGS) pelo apoio financeiro e bolsas de estudo concedidas.

\section{REFERÊNCIAS}

BARBARO, L.A. et al. Utilización de azufre micronizado en la corrección del $\mathrm{pH}$ de compost de residuos de poda. Agriscientia, v.27, p.125-130, 2010. Disponível em: <http://www.scielo.org.ar/
scielo.php?script=sci_arttext\&pid=S1668-298X2010000200008>. Acesso em: 13 nov. 2012.

CAMPBELL, C.A. et al. Potentially mineralizable nitrogen, decomposition rates and their relationship to temperature for five Queensland soils. Australian Journal of Soil Research, v.19, p.323-332, 1981. Disponível em: <http://www.publish. csiro.au/paper/SR9810323>. Acesso em: 16 out. 2012. doi: 10.1071/SR9810323.

CARRIÓN, C. et al. Acidification of compost from agricultural wastes to prepare nursery potting mixtures. ISHS Acta Horticulturae, v.779, p.333-340. 2008. Disponível em: <http:// www.actahort.org/books/779/779_41.htm>. Acesso em: 13 nov. 2012 .

CAVINS, T.J. et al. Monitoring and managing $\mathbf{p H}$ and EC using PourThru Extraction Method. Raleigh: North Caroline State University, 2000.17p. (Horticulture Inform. Leaflet 590). Disponível em: <http://www.ncsu.edu/project/ hortsublab/pdf/PourThru_Master_HIL.pdf $>$. Acesso em: 20 nov. 2012.

FOCHESATO, M.L. et al. Alterações das características químicas de três substratos comerciais na produção de mudas cítricas. Ciência e Agrotecnologia, v.32, n.4, p.10401046, 2008. Disponível em: <http://www.scielo.br/scielo. php? script $=$ sci_arttext $\&$ pid $=$ S 1413-70542008000400002>. Acesso em: 12 set. 2012. doi: 10.1590/S141370542008000400002 .

HEYDARNEZHAD, F. et al. Influence of elemental sulfur and sulfur oxidizing bacteria on some nutrient deficiency in calcareous soils. International Journal of Agriculture and Crop Sciences, v.4, n.12, p.735-739, 2012. Disponível em: <http://ijagcs.com/wp-content/uploads/2012/09/735-739.pdf>. Acesso em: 14 nov. 2012.

KÄMPF, A.N. et al. Lowering $\mathrm{pH}$ value with elemental sulfur in the substrate for ex vitro acclimatization. Acta Horticulture 
(ISHS), v.812, p.15-420, 2009. Disponível em: <http://www. actahort.org/members/showpdf?booknrarnr=812_58>. Acesso em: 05 nov. 2012.

KÄMPF, A.N. Preparo do substrato para a produção de plantas ornamentais. In: KÄMPF, A.N. Produção comercial de plantas ornamentais. Guaíba: Agropecuária, 2005. p.45-88.

LINDEMANN, W. et al. Effect of sulfur source on sulfur oxidation. Soil Science Society of America Journal, v.55, p.85-90, 1991. Disponível em: <https://dl.sciencesocieties.org/publications/sssaj/ abstracts $/ 55 / 1 /$ S S 0550010085 ? access $=0 \& v i e w=p d f>$ Acesso em: 12set. 2012. doi: 10.2136/sssaj1991.03615 $995005500010015 x$.

MAGALHÃES, R. et al. Uso de enxofre para correção do pH de composto orgânico. In: SALÃO DE INICIAÇÃO CIENTÍFICA UFRGS, 13., 2005, Porto Alegre, RS. Anais... Porto Alegre: ROPESQ, 2005. CD-Resumos.
ORMAN, S.; KAPLAN, M. Effects of elemental sulfur and farmyard manure on $\mathrm{pH}$ and salinity of calcareous sandy loam soil and some nutrient elements in tomato plant. Journal of Agricultural Science and Technology, v.5, p.20-26, 2011. Disponível em: $<$ file://C:/Users/Vinicius/Downloads/273242011081777594921. pdf>. Acesso em: 20 nov. 2012.

SCHMITZ, J.A.K. et al. Propriedades químicas e físicas de substratos de origem mineral e orgânica para o cultivo de mudas em recipientes. Ciência Rural, v.32, n.6, p.937-944, 2002. Disponível em: <http://dx.doi.org/10.1590/S010384782002000600005>. Acesso em: 14 ago. 2012. doi: 10.1590/ S0103-84782002000600005.

SIERRA, C.B. et al. Azufre elemental como corrector del $\mathrm{pH}$ y la fertilidad de algunos suelos de la III y IV región de chile. Agricultura Técnica, v.67,n.2, p.173-181, 2007. Disponível em: <http://dx.doi.org/10.4067/S036528072007000200007>. Acesso em: 02 nov. 2012. doi: 10.4067/ S0365-28072007000200007. 